\title{
Effect of chain flexibility in the network structure on the viscoelasticity of epoxy thermosets
}

\author{
John S. Nakka • K. M. B. Jansen • L. J. Ernst
}

Received: 8 November 2010 / Accepted: 27 February 2011 /Published online: 16 March 2011

(C) The Author(s) 2011. This article is published with open access at SpringerLink.com

\begin{abstract}
In this paper a detailed study in investigating the effect of the chain flexibility in epoxy-amine crosslinked network is done. In order to introduce flexibility into the crosslinked network a homologous series of four aliphatic diamine curing agents varying only in the chain length and having a constant functionality $(f=4)$ is taken and cured stoichiometrically with aromatic epoxy $(f=2)$ resin. For each of the cured mixture the viscoelastic master curve and corresponding shift factors were determined. It is found the introduction of flexibility shifts the viscoelastic curves by 5 decades with respect to frequency scale. This shift in the viscoelastic curve is modeled with a parameterized Havriliak-Negami model for the master curve. The free volume contribution for the changes in the coefficient of thermal expansion at $T_{g}$ is also determined.
\end{abstract}

Keywords Resin · Functionality · Thermosets · Crosslink density · Flexibility · Viscoelasticity $\cdot$ Rubber elasticity

\section{Introduction}

Thermosets are polymeric materials whose properties (mechanical, thermal, etc) depend on time and temperature. The dependence of the thermoset properties with time and temperature is termed as viscoelasticity and plays an vital role in the long term performance of thermosets. The position of the viscoelastic transition region is characteristic for the determining the thermo-mechanical properties of

J. S. Nakka $(\varangle) \cdot$ K. M. B. Jansen $\cdot$ L. J. Ernst

Delft University of Technology,

Mekelweg 2,

2628 CD, Delft, The Netherlands

e-mail: j.s.nakka@tudelft.nl these thermoset materials. The viscoelasticity (or viscoelastic response) of thermosets depends mainly on the network structure which is formed after the cure reaction between the resin and curing agent. The network structure formed depends on the properties of initial reacting resin-curing agent. The viscoelastic response of epoxy resins cured with various curing agents has been studied in the past by many researchers $[1,6,19]$. From our previous studies and also from other research work it was found that the viscoelastic response of the cured epoxies is sensitive to the variation of the reacting mixture (or group) functionalities, mixing ratios, conversion, curing conditions and the crosslink density of the network formed $[9,11,14,15]$.

Flexibility of the network structure is another important parameter which can effect the position of viscoelastic transition region and can be determined using DiMarzio's approach [2].

In this paper a model is proposed which relates the chemistry of the reacting resin-hardener mixtures to the final viscoelastic behavior. The proposed model can be achieved in two steps. First we assume that the governing factor to predict the viscoelastic properties of thermosets is the crosslink density. Since the crosslink density is a function of the reacting functional groups, mixing ratio and conversion, these inputs have to be determined. Theoretically, the crosslink density can be predicted by the Macosko and Miller theory [12] and experimentally it can be estimated from the rubbery modulus using the concept of rubber elasticity. In the second step we use the calculated crosslink density to predict the shape of the viscoelastic master curve.

In order to investigate the effect of network flexibility on the viscoelasticity, stoichiometric ratios of aromatic epoxy $(f=2)$ and homologous series of amines having constant functionalities are cured such that full conversion of the 
epoxy groups are achieved. The fully cured products are then tested for their thermo-mechanical properties in tension mode in the Dynamic Mechanical Analyser $(D M A)$. Time-temperature-superposition (TTS) is applied to the data obtained from the DMA tests. We then parameterize the shape changes of the relaxation master curves. This result in a attaining a set of parameters such as the glassy, rubbery modulus, the position (relaxation time constant) and the shape of the glass transition region. The obtained parameters are then related to the crosslink density. The Havriliak-Negami fit function is used to describe the viscoelastic behavior of these cured resin systems.

In our previous study [14] a model system is selected based on epoxy-amine system. The model system contains an epoxy (BADGE) and three different amines. The functionality $\left(f_{E}\right)$ of the initial selected epoxy reactant has EEW of 175 and a functionality of 2 i.e., $f_{E}=2$. Three types of amines are selected in which the functionality of the amine is varied from $f_{A}=2$ to $f_{A}=4$. The BADGE is mixed with the three amines independently. The independent reactions of the epoxy with the three amines is done such that $100 \%$ epoxy reaction is achieved. Three types of solid epoxy samples are obtained after the three independent reactions. The epoxy samples are then characterized for their viscoelastic properties in the $D M A$. It was observed that the increase in the functionality of the amine from $f_{A}=2$ to $f_{A}=4$ has increased the rubbery modulus $\left(E_{\mathrm{r}}\right)$ (at $T_{\mathrm{g}}+30$ ) from $9 \mathrm{MPa}$ to $35 \mathrm{MPa}$. While the $T_{\mathrm{g}}$ increased from $93^{\circ} \mathrm{C}$ to $136^{\circ} \mathrm{C}$ (i.e., increase of $43^{\circ} \mathrm{C}$ ). The change in the rubbery modulus and $T_{\mathrm{g}}$ is mainly due to the change in the crosslink density values from $1104 \mathrm{~mol} / \mathrm{m}^{3}$ to $3270 \mathrm{~mol} / \mathrm{m}^{3}$.

For the present study, our understanding is that by increasing the chain length in the amine reactant increases the flexibility within the crosslinked epoxy-amine network. Also, as the functionality of the epoxy and amine reactants does not change and therefore the the crosslink density of the epoxy-amine network formed is slightly affected.
Further, it is expected that the properties such as $T_{g}$, free volume, Coefficient of thermal expansion (CTE) etc will change. So, a systematic variation in the chain length of the amine reactant can be exploited to understand the changes in the physical properties i.e., $T_{g}$, free volume, CTE etc.

The aim of this paper is to understand the effect of the varying the chain length (or spacer length) of the initial resin chemistry on the final properties of their cured products. This understanding gives a firsthand estimate of the final properties and thereby saves time for the characterization of polymeric materials which is tedious. Moreover, if a good understanding of the relation between the resin chemistry and the final properties of the cured product is known then it would be possible to be able to predict the properties and furthermore to tailor the properties of the polymeric materials.

\section{Experimental}

\section{Materials}

Bisphenol A diglycidyl ether (DER 332, 97\%) and four aliphatic amine curing agents EDA (1,2-Diamino ethane, $99 \%$ pure), BDA (1,4-Diamino butane, $98 \%$ pure), HDA (1,6-Diamino hexane, 98\% pure), ODA (1, 8-Diamino hexane, 99\% pure) were purchased from Sigma-Aldrich Logistik GmbH, Schnelldorf, Germany. These materials were not purified and used as received. The chemical structures of the epoxy and amines are shown in Fig. 1 and the curing reaction between them is shown Fig. 2. The amino curing agents consists of $2,4,6 \& 8$ respectively of methylene spacer groups.

\section{Sample preparation}

Neat resin castings for DMA studies were prepared in aluminum moulds. The aluminum mould consist of an
Fig. 1 Shows the compound name, structure, average functionality $(f)$ of the epoxy and four aliphatic amines a.

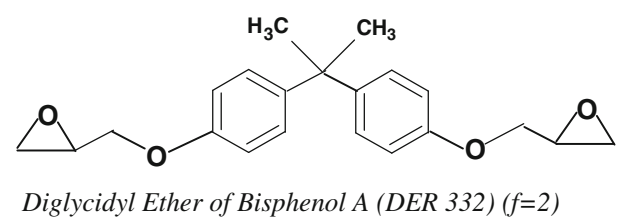

c.

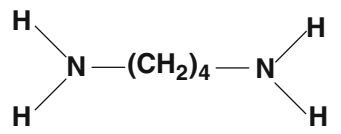

1,4-Diamino butane $(f=4)$ d.<smiles>CCCCCCCC</smiles>

1,6-Diamino hexane $(f=4)$ b.<smiles>CNCCCN</smiles>

e.<smiles>CCCCCCCC</smiles>

1,8-Diamino octane $(f=4)$ 
Fig. 2 a. Epoxide ring-opening reaction with primary amine $\mathbf{b}$. Epoxide ring-opening reaction with secondary amine,

c. Etherification reaction between hydroxyl group of reacted epoxy and unreacted epoxy groups (usually occurs at temperature above $100^{\circ} \mathrm{C}$ ) (or) homo polymerisation of epoxy a.<smiles></smiles>

b.<smiles>[2H]NC[C@H](C)O</smiles>

c.<smiles>[R7]N([R7])C[C@H](C)O</smiles>

aluminum insert with gaps of dimension $6.0 \times 1.5 \times 3 \mathrm{~mm}$ and is fastened in between two aluminum plates into which the premixed resin is poured and cured at different curing schedules. High temperature mirror glaze wax, (Meguiar's Inc., Irvine, U.S.A) is used as mould releasing agent. Firstly, a known amount of epoxy resin (DER 332) is taken in a beaker. Since the epoxy partly crystallizes at room temperature it is heated at $80^{\circ} \mathrm{C}$ for half an hour so that the epoxy crystals melt and also the absorbed moisture is removed. To this a stoichiometric amount of amines is added and mixed thoroughly. The prepared mixture is then cast in the aluminium mould. Then they are cured and post cured at different temperatures to obtain full conversion of the epoxy. Cured samples of stoichiometrically mixed amines and epoxy are prepared with different mixing ratios and cure schedules. For all formulations containing different mixing ratios curing is done initially at $80^{\circ} \mathrm{C}$ for $3 \mathrm{~h}$ and $100 \mathrm{C}$ for $1 \mathrm{~h}$ and then post cured. Table 1 shows the different stoichiometric mixing ratios and post curing temperatures. Preliminary measurements showed that too high post cure temperature for the lower functionality resins resulted in the undesired etherification reaction shown in Fig. 2c. In order to avoid this etherification all the mixtures were post cured for $4 \mathrm{~h}$ at $150^{\circ} \mathrm{C}$.

\section{Viscoelastic measurement}

A TA-Instruments Q800 model (Dynamic Mechanical Analyzer) was used. Viscoelastic study of cured resins was done on rectangular bars of cured specimen's in tension mode at different frequency sweeps $(0.3-60 \mathrm{~Hz})$ with a heating rate $1^{\circ} \mathrm{C} \min ^{-1}$. Evolution of storage modulus $\left(E^{\prime}\right)$ and energy dissipation (Tan $\delta$ ) with temperature was measured. The resulting viscoelastic data is then shifted along the frequency axis to obtain both a master curve and the corresponding shift factor curve.

\section{Density}

The densities of the cured resins are measured using the Archimedes principle that states that the volume is proportional to the difference in weight between a dry and submerged sample. The experimental set up consists of
Table 1 Shows the sample name, average functionality, composition, post cure schedule and the molecular weight between crosslinks for the post cured samples

\begin{tabular}{lllll}
\hline Sample name & $\mathrm{f}$ & Stoichiometric mixing ratio & Post cure & $\mathrm{M}_{\mathrm{C}}(\mathrm{g} / \mathrm{mol})$ \\
\hline CL2 & 4 & 1 DER332+1 EDA & $4 \mathrm{~h} @ 150^{\circ} \mathrm{C}$ & 307 \\
CL4 & 4 & 1DER332+1 BDA & $4 \mathrm{~h} @ 150^{\circ} \mathrm{C}$ & 380 \\
CL6 & 4 & 1 DER332+1 HDA & $4 \mathrm{~h} @ 150^{\circ} \mathrm{C}$ & 390 \\
CL8 & 4 & 1DER332+1 ODA & $4 \mathrm{~h} @ 150^{\circ} \mathrm{C}$ & 410 \\
\hline
\end{tabular}


weighing balance and glass filled with silicone oil (Type: M100, Dow Corning). The sample weight is determined both in air and oil. The density is calculated using Eq. 1.

$\operatorname{Density}(\rho)=\frac{\rho_{\text {oil }} \times \text { Sample }_{\mathrm{dry}}}{\text { Sample }_{\mathrm{dry}}-\text { Sample }_{\mathrm{wet}}}$

$\rho_{\text {oil }}$ is the density of silicone oil $\left(0.965 \mathrm{~g} / \mathrm{cm}^{3}\right)$, Sample Sry $_{\text {is }}$ is the weight in grams of the sample in air and Sample wet is the weight in grams of the sample in silicone oil. The test procedure was calibrated with polystyrene and polycarbonate samples of known density.

\section{Coefficient of linear thermal expansion measurement $\left(\alpha_{L}\right)$}

The coefficient of linear thermal expansion, $\alpha$, is determined using a thermo mechanical analyzer (TMA) and is shown by the Eq. 2 . The temperature range was from RT$180^{\circ} \mathrm{C}$ and the heating rate $10^{\circ} \mathrm{C} / \mathrm{min}$. The measurement of $\alpha_{L}$ is always done in the second heat scan

$\alpha_{L}=\left(1 / L_{0}\right)(\Delta L / \Delta T)$

Where $\Delta L / \Delta T$ is the slope of the dimensional changetemperature curve and $L_{0}$ is the initial length.

\section{Calculation of the properties}

Average functionality and stoichiometric ratio

Let us consider an arbitrary mixture of polydisperse monomers $A_{i}$ with $f_{i}$ functional groups and monomers $B_{j}$ with $g_{j}$ functional groups. The number average functionalities then become

$\bar{f}_{n, A}=\frac{\sum n_{A i 0} f_{i}}{\sum n_{A i 0}}, \bar{g}_{n, B}=\frac{\sum n_{B j 0} g_{j}}{\sum n_{B j 0}}$

in which $n_{A i 0}$ and $n_{B j 0}$ denote the initial number of moles of $A_{i}$ and $B_{j}$ monomers, respectively. For future use we also define the mole fractions of crosslinkable $\mathrm{A}$ and $\mathrm{B}$ groups $a_{i}$ and $b_{j}$ as

$a_{i}=\frac{n_{A i 0} f_{i}}{\sum n_{A i 0} f_{i}}, b_{j}=\frac{n_{B j 0} g_{j}}{\sum n_{B j 0} g_{j}}$

and the stoichiometric ratio as the initial ratio of all available A groups to those of all B groups

$r_{A}=\frac{\text { initial no. A groups }}{\text { initial no. B groups }}=\frac{\sum n_{A i 0} f_{i}}{\sum n_{B j 0} g_{j}}$

For equal numbers of $\mathrm{A}$ and $\mathrm{B}$ groups this ratio equals unity. Consider now the case that there are more B groups available $\left(r_{A}<1\right)$ and that the $\mathrm{A}$ groups have reacted to extent $p_{A}$ (defined as the number of reacted $\mathrm{A}$ groups divided by the initial number of A groups). Since the number of reacted $\mathrm{B}$ groups equals that of the reacted $\mathrm{A}$ groups the conversion of $\mathrm{B}$, denoted as $p_{B}$, can then be expressed as

$p_{B}=\frac{\text { no.reacted B groups }}{\text { initial no. B groups }}=\frac{\text { no.reacted A groups }}{\text { initial no. B groups }}=p_{A} r$

Crosslink density

In order to relate the resin chemistry to viscoelastic behavior the crosslink density has to be determined. Calculated Cross-link density $\left(v_{c}^{\text {calc }}\right)$, which is a function of conversion $\left(p_{A}\right)$, mixing ratio $\left(\mathrm{r}_{\mathrm{A}}\right)$ and functionality $\left(f_{i}\right)$ can be determined from the Miller and Macosko theory [12, 13], and is given by the relation

$v_{c}^{\text {calc }}=\frac{\sum_{m=3}^{f_{k}} \frac{m-2}{2} \sum_{f_{i}=m}^{f_{k}} n_{A i 0} P_{m, f_{i}}(x)}{V}$

Where $n_{\mathrm{Ai} 0}$ is the molar concentration of $A_{\mathrm{f},} V$ is the network volume related to mass network $\left(M_{n}\right)$ and density $(\rho)$ of the fully cured epoxy material as shown in Eq. 8 [19]

$V=\frac{M_{n}}{\rho}$

and $P_{m, f i}(x)$ and the probability that an $A_{f}$ monomer has become an effective crosslink of degree $m$ given by relations

$P_{m, f_{i}}(x)=\left(\begin{array}{c}f_{i} \\ m\end{array}\right) x^{f_{i}-m}(1-x)^{m}$

and $x$ stands for the probability that a randomly picked $\mathrm{A}_{\mathrm{f}}$ group is connected to a finite chain (dangling end). This quantity follows by solving

$p_{A} \sum b_{j}\left[1-r_{A} p_{A}\left(1-\sum a_{i} x^{f_{i}-1}\right)\right]^{g_{j}-1}-x-p_{A}+1=0$

Where $0<x<1$. A numerical solution for $x$ is readily obtained with mathematical tools like MatLab. For the present model system $\mathrm{B}_{2+} \mathrm{A}_{4}$, the value of $\mathrm{x}$ is determined by solving the Eq. 11 .

$x^{3}-\left(1 / p^{2}\right) x-1+1 / p^{2}=0$

Where $p$ is the conversion of epoxy. A detailed study for calculating the crosslink density is available in the literature [9]. 


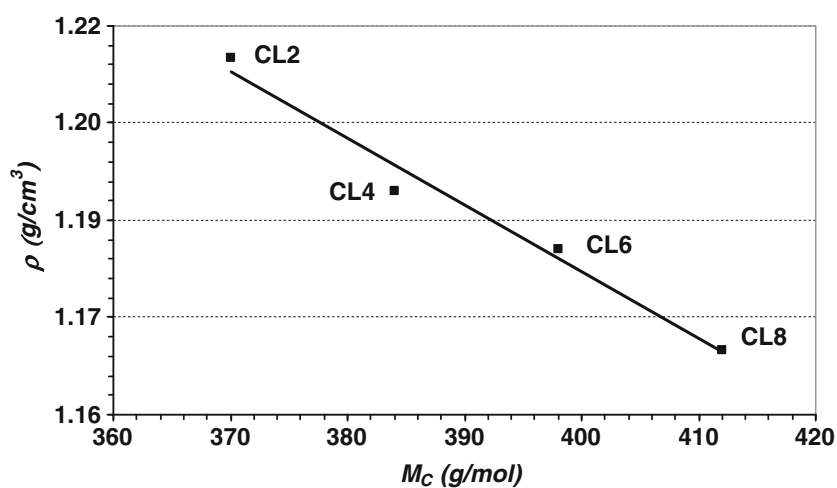

Fig. 3 Density versus Molecular weight between crosslinks $\left(M_{C}\right)$. The filled symbols with thick line indicate the density values and its linear fit. The numbers CL2 to CL8 corresponds to the amount of methylene spacer groups

Molecular weight between crossliks $\left(\mathrm{M}_{\mathrm{C}}\right)$

The molecular weight between crosslinks $\left(M_{C}\right)$ can be calculated using Eq. 12 [4]

$M_{C}=\frac{2\left(M_{e}+\sum_{f=2}^{\infty} \frac{M_{f}}{f} \Phi_{f}\right)}{\sum_{f=3}^{\infty} \Phi_{f}}$

Where $M_{e}$ is the epoxide equivalent weight of the resin, $f$ is the functionality of the amine, $M_{f}$ is the molecular weight of the $f$-th functional amine, and $\Phi_{f}$ is the mol fraction of amine hydrogens provided by the $f$-th functional amine.

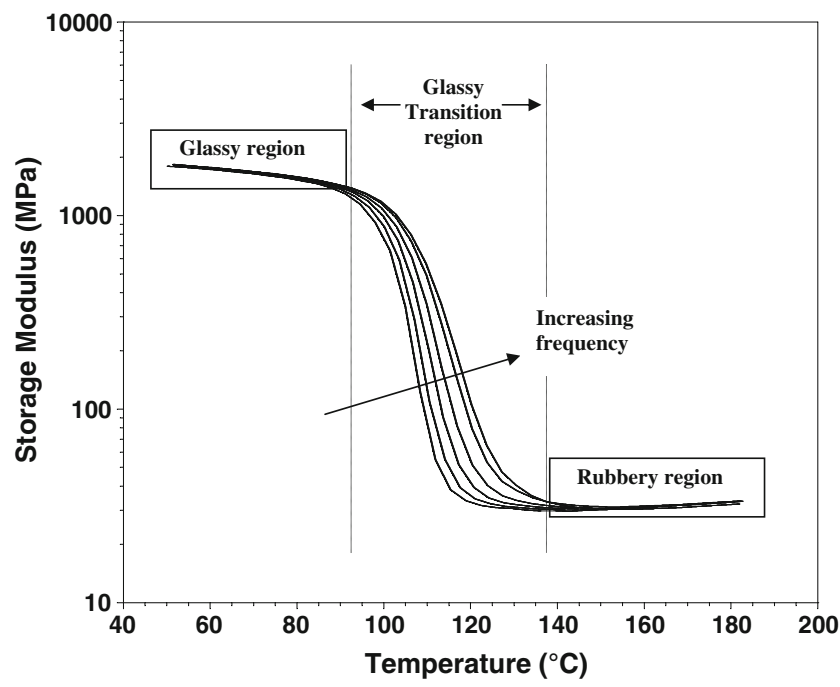

Fig. 4 Plot of storage modulus $E^{\prime}(\omega)$ versus temperature for the CL2 sample. Each line corresponds to the modulus response with respect to temperature for different frequencies

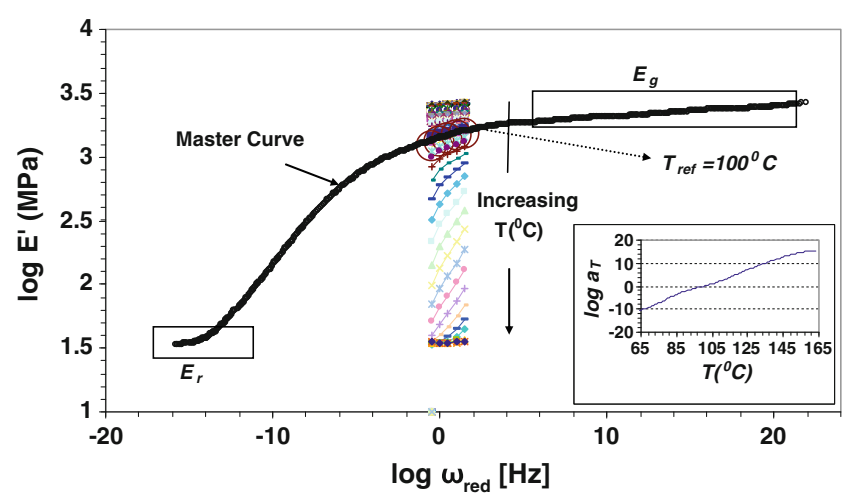

Fig. 5 Plot of storage modulus $\left(E^{\prime}\right)$ with respect to reduced frequency $\left(\omega_{\text {red }}\right)$ for CL2 sample. $E_{g}, E_{r}$ and $T_{\text {ref }}$ are the glassy modulus, rubbery modulus and reference temperature $\left(100^{\circ} \mathrm{C}\right.$ [indicated by circles]. The lines with symbols are modulus values of all frequencies at different temperature. Master curve shown by full line. A plot of shift factor $\left(\log \mathrm{a}_{\mathrm{T}}\right)$ versus temperature is shown as an insert

Glass transition temperature $\left(\mathrm{T}_{\mathrm{g}}\right)$

One way of defining the glass transition temperature is by determining the temperature at the peak maximum of the Tan $\delta$ curve for $1 \mathrm{~Hz}$ and is denoted by $T_{g(D M A)}$ in this paper. Further, the glass transition temperature can also be predicted using DiMarzio equation and is denoted by $T_{g}$ (Dimarzio) and is defined by Eq. 13 .

$T_{g(\text { Dimarzio })}=\frac{T_{g l}}{\left(1-K_{D M} F \nu_{c}^{\text {calc }}\right)}$

Where $T_{g l}$ is the $T_{g}$ of the uncrosslinked or linear polymer chain, $K_{D M}$ is constant, $F$ is the flexibility

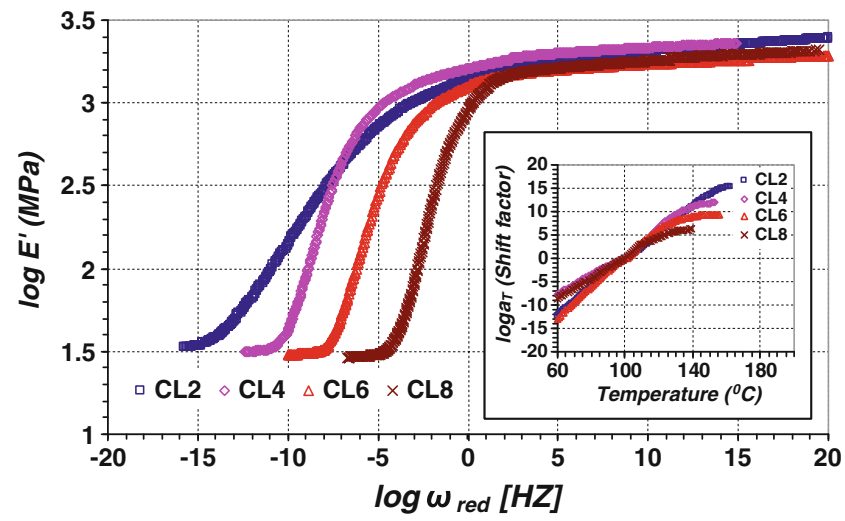

Fig. 6 Plot of master curves obtained after frequency-temperature superposition to a reference temperature $\left(T_{r e f}=100^{\circ} \mathrm{C}\right)$ of the increasing network chain length with respect to the reduced frequency $\left(\omega_{\text {red }}\right)$. The shift factor $\left(\log a_{\mathrm{T}}\right)$ curves corresponding to the obtained master curves of varying chain length with respect to the temperature is shown as an insert 


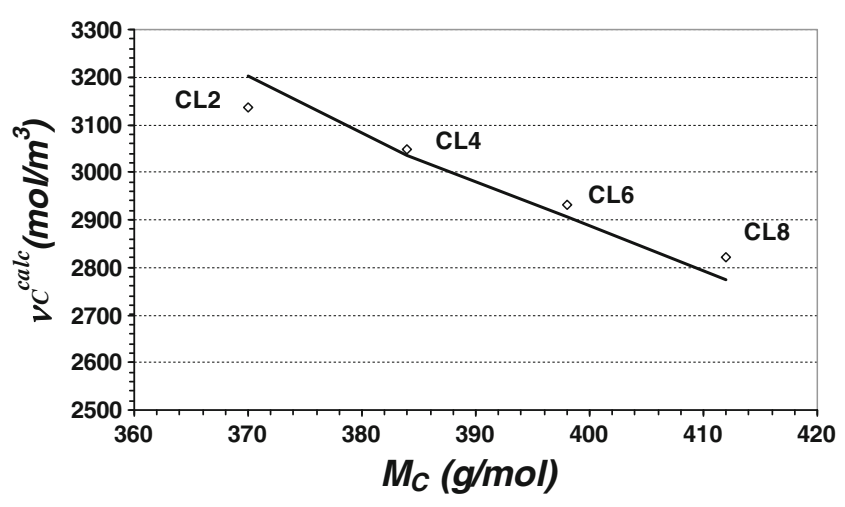

Fig. 7 Crosslink density versus Molecular weight between crosslinks $\left(\mathrm{M}_{\mathrm{C}}\right)$. The unfilled symbols indicate the Measured crosslink density $\left.\begin{array}{l}\left(v_{C}^{\text {Meas. }}\right) \\ \left(v_{C}^{\text {calc }}\right)\end{array}\right)$ and the thick line indicates Calculated crosslink density

parameter in $\mathrm{g} / \mathrm{mole}$ and $v_{c}^{\text {calc }}$ is the calculated crosslink density in mole/g. The eq. 13 can be written as

$T_{g(\text { Dimarzio })}=T_{g l}\left(1+\frac{K_{D M} F_{c}^{\text {calc }}}{1-K_{D M} F v_{c}^{\text {calc }}}\right)$

The Eq. 14 is similar to Fox-Losheak equation [5] as shown by Eq. 15

$T_{g}=T_{g}^{\infty}\left(1+K_{F L}\left[\frac{v_{c}^{\text {calc }}}{1-v_{c}^{\text {calc }}}\right]\right)$

Where $\mathrm{K}_{\mathrm{FL}}$ is constant.

\section{Results and discussion}

Density studies

From Fig. 3 it can be seen the density decreases linearly with the increase in the molecular weight between cross-

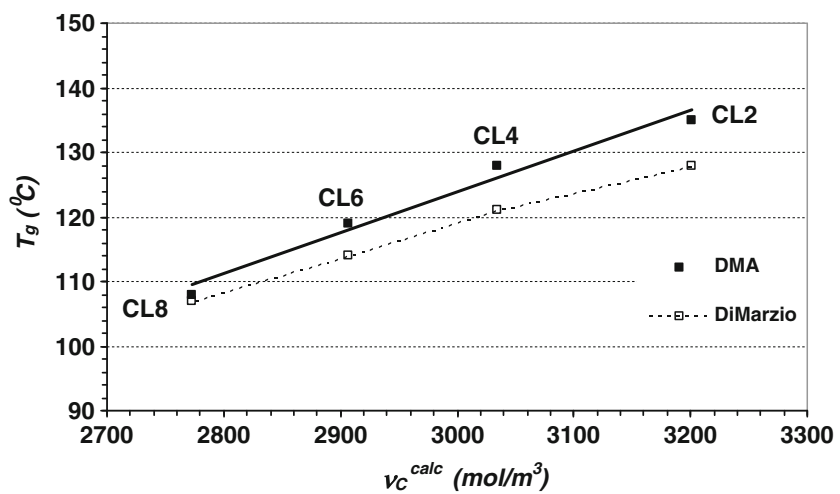

Fig. $8 \mathrm{~T}_{\mathrm{g}}$ versus calculated crosslink density $\left(v_{C}^{\text {calc }}\right)$. The filled symbols with thick line indicate the $\mathrm{T}_{\mathrm{g}(\mathrm{DMA})}$ values and its linear fit (shown by equation). Similarly, the empty symbols, dotted line indicate $\mathrm{T}_{\mathrm{g}(\text { Dimarzio })}$ and its linear fit links $\left(M_{C}\right)$. This can be due to the increase in the chain length of the amine curing agent the hydrophobic nature increases. The increase in hydrophobic nature seperates the polar amine groups and will therefore decrease the density of the cured epoxy network.

\section{DMA studies}

Figure 4 shows the experimental storage modulus data versus the temperature at different frequencies $(0.32,1,3.2$, 32 and $60 \mathrm{~Hz}$ ). The experimental storage modulus contains three regions i.e., glassy plateau, rubbery plateau and transition region. The modulus in the glassy plateau is termed as glassy modulus and denoted by $E_{g}$. Rubbery modulus $\left(E_{r}\right)$ is defined as the modulus in the rubbery region. The glass transition temperature $T_{g}$ from DMA experiments can be determined from the storage modulus, Loss modulus and Tan $\delta$ curves. The glass transition temperature $T_{g}$ in this paper is determined using the $\operatorname{Tan} \delta$ curve and is denoted by $T_{g(D M A)}$. The $T_{g(D M A)}$ is the temperature at the peak maximum of the $\operatorname{Tan} \delta$ curve for $1 \mathrm{~Hz}$. Since, epoxy thermoset materials are polymeric materials whose properties vary with temperature as well as time, the incorporation of time (or frequency) dependency on the viscolelasticity is very important. This can be done by constructing a viscoelastic master curve. Therefore, the storage modulus data at different temperatures from the $D M A$ experiment is plotted with respect to frequency scale in as shown in Fig. 5. According to Time Temperature Superposition principle [10] the modulus data can be shifted along the frequency axis to generate a so-called master curve (included in Fig. 5). Figure 5 shows the storage modulus master curve plotted against reduced angular frequency $\left(\omega_{\text {red }}\right)$ for CL2 formulation obtained after shifting the modulus data on frequency to a reference temperature $\left(T_{\text {ref }}=100^{\circ} \mathrm{C}\right)$ [17]. Where $\omega_{\text {red }}$ is given by

$\omega_{\text {red }}=\frac{\omega}{a_{\mathrm{T}}}$

And $\omega$ is the angular frequency $(\mathrm{rad} / \mathrm{s})$ and $a_{T}$ is the shift factor. The corresponding shift factor is shown as an insert in Fig. 5. In order to understand the effect of chain length in the cured network the master curves for all the formulations are generated using Time Temperature Superposition principle. The storage modulus master curves and their corresponding shift factor curves for all our formulations are obtained by shifting modulus data towards a reference temperature $\left(T_{r e f}=100^{\circ} \mathrm{C}\right)$ and shown in Fig. 6. We can see that the viscoelastic transition region has shifted to higher frequency scales with the increase in network chain length. Note that the glass transition shifts from -7 to -2 from CL2 to CL8 curve with respect to angular frequency. This means that there is a shift of 5 decades along frequency axis. Also 
Table 2 Shows the sample name, Glassy modulus, Rubbery modulus, Measured crosslink density

\begin{tabular}{lllllll}
\hline Sample name & $\begin{array}{l}\text { Glassy modulus } \\
\mathrm{E}_{\mathrm{g}}[\mathrm{MPa}]\end{array}$ & $\begin{array}{l}\text { Rubbery modulus } \\
\mathrm{E}_{\mathrm{r}}[\mathrm{MPa}]\end{array}$ & $\begin{array}{l}v_{c}^{\text {Meas }} \\
\mathrm{mol} / \mathrm{m}^{3} \\
\mathrm{Eq.} 17\end{array}$ & $\begin{array}{l}v_{c}^{\text {Calc }} \\
\mathrm{mol} / \mathrm{m}^{3} \\
\mathrm{Eq.}\end{array}$ & Flexibility (g/mole) & Fractional free volume (f $\left.\mathrm{f}_{\mathrm{g}}\right)$ at $\mathrm{T}_{\mathrm{g}}$ \\
\hline CL2 & 1898 & 35 & 3135 & 3201 & 22.11 & 0.04692 \\
CL4 & 1891 & 33 & 3048 & 3034 & 22.73 & 0.04932 \\
CL6 & 1770 & 31 & 2931 & 2907 & 23.00 & 0.05370 \\
CL8 & 1789 & 29 & 2822 & 2773 & 23.15 & 0.05709 \\
\hline
\end{tabular}

Calculated crosslink density, Flexibility parameter, Fractional free volume of varying chain length

Fig. 6 shows that the shift factor $\left(\log a_{T}\right)$ curves shifts to lower temperatures with increase the network chain length.

From Fig. 6 it can be observed that the glassy modulus is independent of increase in the chain length of the network. This is because below the $T_{g}$ the molecular motion is limited and hence the network chain length has no effect. From Fig. 6 it can be seen that the rubbery modulus slightly decreases with increasing chain length (around 5MPa) which is within experimental scatter and hence can be considered as constant. According to the theory of rubber elasticity, the rubbery modulus [9] is directly proportional to the crosslink density

$E_{r}=3 \mathrm{~A} v_{c}^{\text {meas }} R T$

Where $\mathrm{A}$ is the front factor often assumed to be unity, $R=$ $8.314 \mathrm{~J} / \mathrm{mol} / \mathrm{K}, \mathrm{T}$ is the absolute temperature in $\mathrm{K}$ and $v_{c}^{\text {means }}$ is the measured crosslink density. Since some of the viscoelastic data of our $D M A$ studies showed broad transition region, the modulus at $T_{g}+30^{\circ} \mathrm{C}$ is taken as the rubbery modulus and is the measure of crosslink density. This will be the measured crosslink density. In order to compare the measured and calculated crosslink density results a graph (Fig. 7) is plotted between crosslink density versus $M_{C}$. From Fig. 7 it can be seen that calculated crosslink density agreed

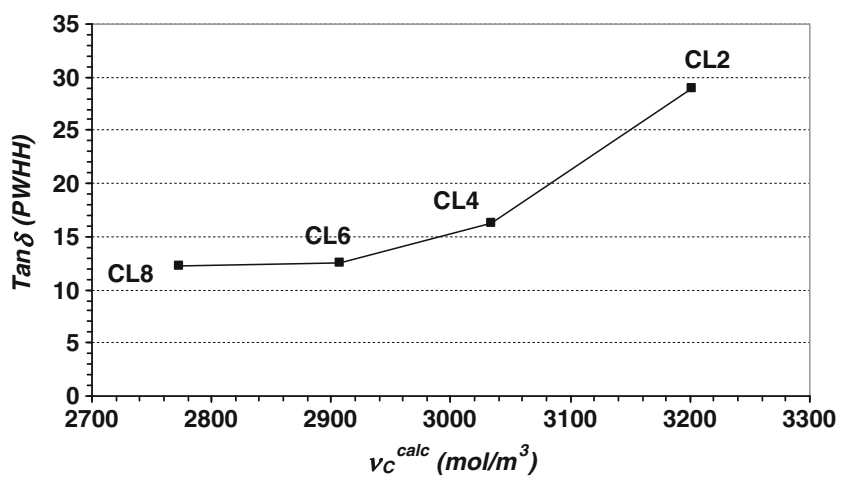

Fig. 9 Plot of Tan delta peak width at half height $\left(\operatorname{Tan}_{(\mathrm{PWHH})}\right)$ for $1 \mathrm{~Hz}$ frequency versus calculated crosslink density $\left(v_{C}^{\text {calc. }}\right)$. The thick line with filled symbols indicates the line connecting the data points (indicated by sample name) relatively well with the measured crosslink density values. The calculated crosslink density $\left(v_{c}^{\text {calc }}\right)$ and measured crosslink density $\left(v_{c}^{\text {meas }}\right)$ are expressed in $\mathrm{mol} / \mathrm{m}^{3}$. From Fig.7 it can be seen that there is a slight decrease in the cross-link density with the increase in $M_{C}$.

The DMA results are also used to determine the glass transition temperature $\left(T_{g}\right)$. The glass transition temperature is the temperature for which the $1 \mathrm{~Hz}$ frequency Tan $\delta$ curve shows a maximum [16]. The $T_{g}$ can also be calculated using Dimarzio's approach (Eq. 13). In order to analyze the effect of calculated crosslink density $\left(v_{c}^{\text {calc }}\right)$ on the $T_{g}, v_{c}^{\text {calc }}$ is plotted against the $T_{g}$ and is shown in Fig. 8. The calculated and measured crosslink density values can be compared with theoretical crosslink density of Halary's work [8]. The filled symbols with full lines in Fig. 8 corresponds to the $T_{g}$ (DMA) and its linear fit which shows that the $T_{g}$ has increased linearly from $108^{\circ} \mathrm{C}$ to $136^{\circ} \mathrm{C}$ [i.e., about $28^{\circ} \mathrm{C}$ ] with the increase in the calculated crosslink density $\left(v_{c}^{\text {calc }}\right)$ and this can be modeled by the Eq. 18 [5]

$T_{g}=T_{\mathrm{g} v_{0}}+B v_{c}^{c a l c}$

Where $\mathrm{B}$ is the slope which is the order of $0.0713 \mathrm{C} \mathrm{m}^{3} / \mathrm{mol}$ and $v_{c}^{\text {calc }}$ is the calculated crosslink density. $T_{g \nu 0}$ shows the

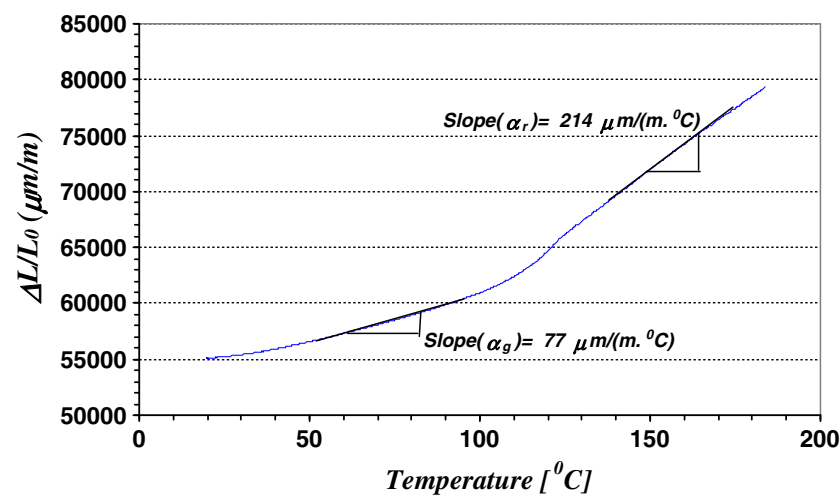

Fig. 10 Typical plot of Dimension change $\left(\Delta \mathrm{L} / \mathrm{L}_{0}\right)$ versus Temperature for the sample name CL6. The slope below and above $T_{g}$ gives the Coefficient of linear thermal expansion of glassy and rubbery regions 


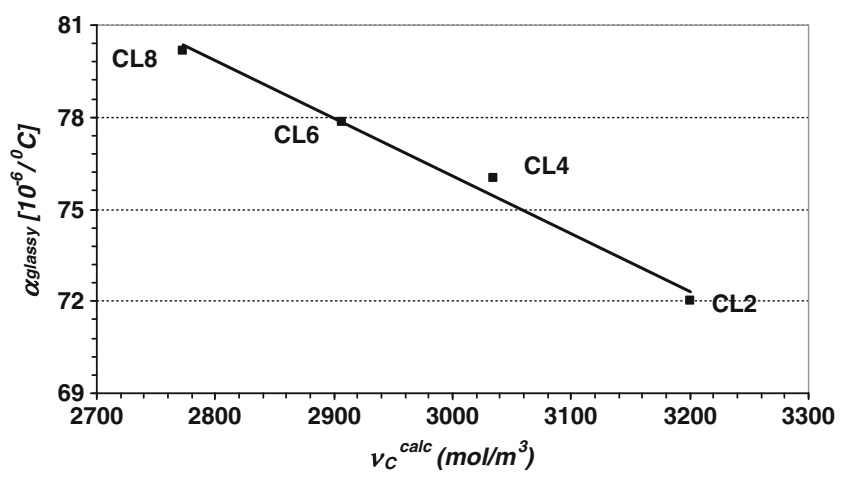

Fig. 11 Plot of Coefficient of thermal expansion in the glassy region $\left(\alpha_{\text {glassy }}\right)$ versus calculated crosslink density $\left(v_{C}^{\text {calc. }}\right)$. The filled symbols are experimental $\alpha_{\mathrm{g}}$ values and the straight line indicates its linear fit

axis offset value, which represents the glass transition for the uncrosslinked linear polymer chains.

The $T_{g}$ can also be predicted using DiMarzio's approach (Eq. 13). The unfilled symbols with dotted lines from Fig. 8 is the predicted $T_{g}$ i.e., $T_{g}$ (Dimarzio) also shows increasing trend in the $T_{g}$ in comparison to $T_{g}(D M A)$. The predicted $T_{g}$ i.e., $T_{g}$ (Dimarzio) are calculated based on the value of $K_{D M}=2.91, v_{c}^{\text {calc }}$ and the $T_{g l}$ determined by Bellenger [3]. In Bellengers [3] work the $T_{g l}$ is determined using Differential Scanning Calorimetry $(D S C)$. Therefore the difference in the $T_{g}$ (DMA) and $T_{g}$ (Dimarzio) values could be because of the determination of $T_{g}$ in different experimental methods. Further, the $T_{g}$ values determined by $D S C$ are always $10-15^{\circ} \mathrm{C}$ lower than the $T_{g}$ determined by $D M A$. Flexibility factor $(F)$ in Dimarzio's equation is calculated using bellenger's approach $[2,3]$ and the values are shown in Table 2. According to DiMarzio hypothesis, the value of $\left(T_{g}-T_{g l}\right) /{ }_{c} T_{g}$ is proportional to $F$. The

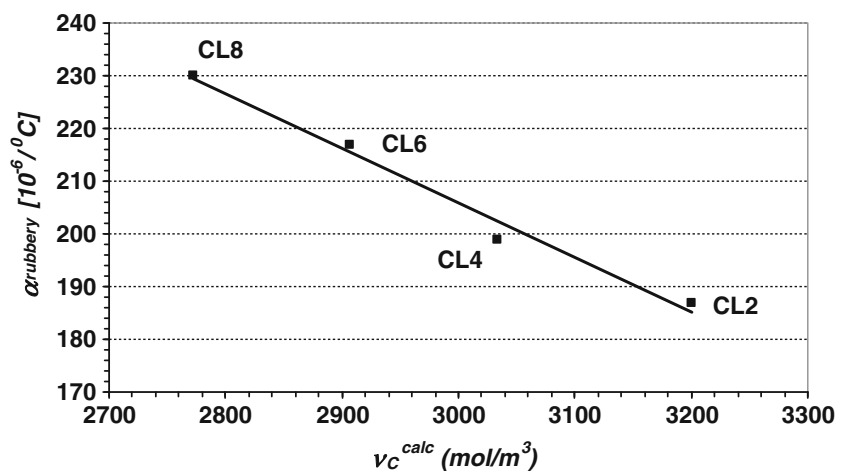

Fig. 12 Plot of Coefficient of thermal expansion in the rubbery region $\left(\alpha_{\text {rubbery }}\right)$ versus calculated crosslink density $\left(v_{C}^{\text {calc. }}\right)$. The filled symbols are experimental $\alpha_{\mathrm{r}}$ values and the straight line indicates its linear fit
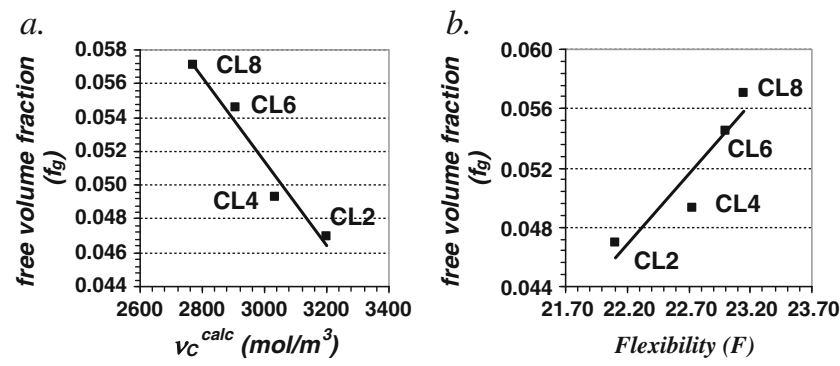

Fig. 13 a. Plot of free volume fraction $\left(f_{g}\right)$ versus calculated crosslink density $\left(v_{C}^{\text {calc. }}\right)$. b. Plot of free volume fraction $\left(f_{g}\right)$ versus Flexibility $(F)$. Note: The filled symbols are experimental values and the straight line indicates their linear fit

flexibility $\mathrm{F}$ is calculated using (Eq. 19)

$F=\frac{\sum N_{i} F_{i}}{\sum N_{i}}$

Where $N_{i}$ is the number of crosslink reactants of type $i$ (whose flex param $F_{i}$ ) in the repeating unit of the network.

Figure 9 shows the Tan $\delta$ peak width at half height (tan $\delta$ $(P W H H)$ for $1 \mathrm{~Hz}$ frequency for all formulations versus calculated crosslink density $\left(v_{c}^{\text {calc }}\right)$. The $\left.\tan \delta_{(P W H H)}\right)$ is the measure of width [units: ${ }^{\circ} \mathrm{C}$ ] of the $\tan \delta$ peak at its half height when plotted against temperature. It can be seen that from Fig. 9 that with small increase in the calculated crosslink density $\left(v_{c}^{\text {calc }}\right)$ the peak width at half height of the $\tan \delta$ peak increases largely. In other words the sample CL8 shows lowest $\tan \delta(P W H H)$ and the sample CL2 shows the highest $\tan \delta(P W H H)$. This trend is mainly because in the CL8 sample the flexibility of network structure is high and hence can undergo relaxation fast with respect to temperature and hence shows lowest $\tan \delta_{(P W H H)}$. Whereas for the

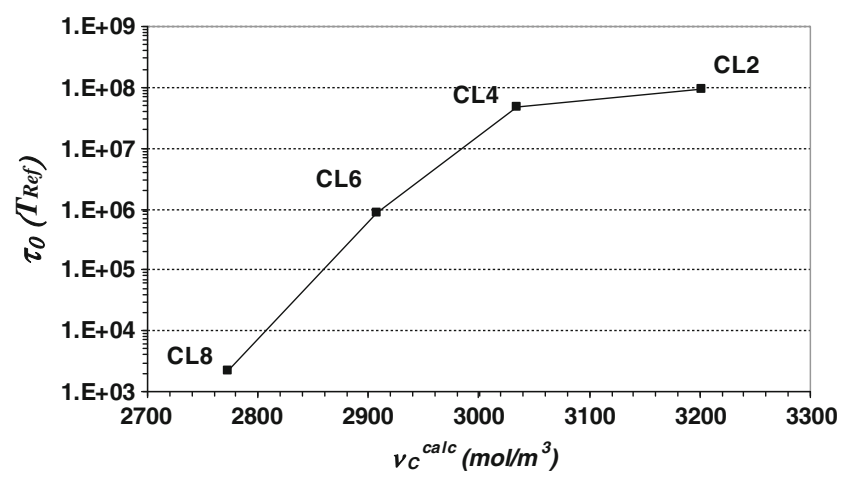

Fig. 14 Plot of relaxation time constant at reference temperature $\left(\mathrm{T}_{\mathrm{ref}}\right.$ $=100^{\circ} \mathrm{C}$ ) versus calculated crosslink density $\left(v_{C}^{\text {calc. }}\right)$. The filled symbols are experimental $\alpha_{\mathrm{r}}$ values and the straight line indicates its linear fit 


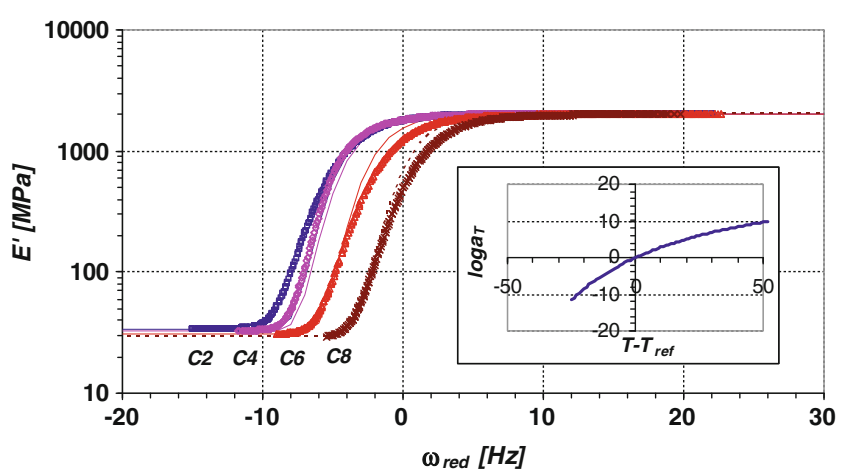

Fig. 15 Master curves for the four formulations obtained after using common shift factor in comparison to the globally fitted master curves (full lines) [taken $\mathrm{T}_{\text {ref }}=100^{\circ} \mathrm{C}$ ]. The shift factor $\left(\log \mathrm{a}_{\mathrm{T}}\right)$ curve with respect to $\mathrm{T}-\mathrm{T}_{\text {ref }}$ is shown as insert

CL2 sample has lowest network flexibility in the sample series and hence has the highest $\tan \delta(P W H H)$.

\section{Coefficient of thermal expansion studies}

Figure 10 shows the typical plot of dimensional change with respect to temperature for the CL6 sample. Since the length-temperature plots are composed of two linear regions below and above $T_{g}$, thermal expansion coefficients in the glassy state $\left(\alpha_{\text {glassy }}\right)$ and in the rubbery state $\left(\alpha_{\text {rubbery }}\right)$ could be determined. From Fig. 11 it can be observed that the coefficient of linear thermal expansion in the glassy region $\left(\alpha_{\text {glassy }}\right)$ decreases with the slight increase in calculated crosslink density $\left(v_{c}^{\text {calc }}\right)$. From Fig. 12 it can be observed that the coefficient of linear thermal expansion in the rubbery region $\left(\alpha_{\text {rubbery }}\right)$ decreases from 230 to 187 $\left[10^{-6} \mathrm{~K}^{-1}\right]$ with the slight increase in calculated crosslink density $\left(v_{c}^{c a l c}\right)$. This is because the fractional free volume $\left(f_{g}\right)$ for the different formulations decreases with the increase in the crosslink density (see Fig. 13a). The fractional free volume is calculated using Simha-Boyer approach [7] and is shown in Table 2. The Simha-Boyer free volume fraction $\left(f_{g}\right)$ at $T_{g}$ is related to the change in the coefficient of thermal expansion and is shown by Eq. 20 .

$f_{g}=\left(\alpha_{r}-\alpha_{g}\right) T_{g}$

Further, from Fig. 13b it can be seen that the fractional free volume $\left(f_{g}\right)$ increases linearly with the increase in the flexibility of the network.

\section{Modeling of relaxation curves}

In order to predict the generated relaxation master curve as discussed earlier the master curve has to be parameterized with a well known fit-function. Therefore, the main features of all the master curves are fitted to Havriliak-Negami (HN) fit function as shown by Eq. 21 [18].

$E^{\prime}=E_{r}+\frac{E_{g}-E_{r}}{\left[1+\left(\omega_{\text {red }} \tau_{0}\right)^{-m}\right]^{n}}$

The HN-fit function is a simple analytical function to describe the measured relaxation master curves and contains five parameters, which are the glassy storage modulus $\left(E_{g}\right)(\mathrm{MPa})$, rubbery modulus $\left(E_{r}\right)(\mathrm{MPa})$, reduced angular frequency $\left(\omega_{\text {red }}\right)(\mathrm{rad} / \mathrm{s})$, position of the transition region $\left(\tau_{0}\right)\left(\mathrm{s}^{-1}\right)$ and power law parameters $m$ and $n$ (shape of transition region). The parameter $n$ is the slope of the transition region and $\mathrm{m}$ is the slope at the end of the transition. In order to compare the different experimental master curves it is necessary to use a common shift factor curve. We can therefore choose $T_{g}$ as the reference temperature and determine WLF (Williams-Landel-Ferry) fit parameters.

$\log a_{T}=\frac{C_{1}^{\mathrm{g}}\left(T-T_{g}\right)}{C_{2}^{\mathrm{g}}+\left(T-T_{g}\right)}$

This common shift factor parameters $C_{1}^{g}, C_{2}^{g}$ are determined to be 25.7, 79.92. It is well known that the relaxation time constant $\tau_{0}$ in Eq. 21 depends strongly on temperature. So, for thermorheological simple materials this temperature dependency can be taken into account with the so called shift function $a_{T}\left(T, T_{\text {ref }}\right)=t_{0}(T) / t_{0}\left(T_{\text {ref }}\right)$. Where $\tau_{0}$ is determined by taking the reference temperature at $100^{\circ} \mathrm{C}$ in the equation below

$\tau_{0}=\tau_{0 g} a_{T}\left(T, T_{g}\left[v_{c}^{c a l c}\right]\right)$

The determined $\tau_{0}$ is plotted against the calculated crosslink density $\left(v_{c}^{\text {Calc }}\right)$ to see the effect of crosslink density on the relaxation time constant. It can be seen from the Fig.14 that the relaxation time constant has increased by 5 decades with the increase in the calculated crosslink density $\left(v_{c}^{\text {Calc }}\right)$. The CL2 sample which is having highest crosslink density shows highest relaxation time constant.

The common shift factors $C_{1}^{g}, C_{2}^{g}$ are used for obtaining new master curves. Further, non-linear curve fitting using the Eq. 21 is done to the new master curves by taking fixed value for $E_{g}$ and different values for $E_{r}$. The shape parameter i.e., $m \& n$ are determined. The values of $\mathrm{m} \& \mathrm{n}$ obtained for all the new master curves are different. Therefore fixing the value of $n=8$ and performing the non-linear curve fitting gives $m=0.25$. Therefore a set of single parameters $E_{g}=2000 \mathrm{MPa}, \tau_{0 g}=$ 
1 [s], $m=0.25, n=8$ are obtained. With this set of parameters global or predicted master curves could be generated for each of the 4 formulations. In Fig. 15 these predictions (full lines) were compared with the experimental new master curve (symbols). We can see that the $\mathrm{HN}$-fit function describes the measured curves relatively well.

\section{Conclusions}

In this paper a model is proposed in order to understand the effect of introduction of flexibility into the network structure by increasing the chain length of reacting mixtures. Bisphenol A epoxy and a homologous series of aliphatic amines varying in their chain length are taken as starting reacting compounds and cured and were tested in DMA for their viscoelastic behavior. It is observed that by systematically varying the chain length of the reacting compounds the crosslink density of cured network varied slightly. The measured and predicted crosslink density values were in agreement to each other. The $T_{g}$ changed by $28^{\circ} \mathrm{C}$ and also the relaxation master curves shifted by 5 decades on the frequency scale within the sample series. This is mainly due to the flexibility of the network chain. The shift of the relaxation master curves was also predicted well using $\mathrm{HN}$-fit function. A single set of 9 parameters $(m, n$, $\left.B, v_{c}^{\text {calc }}, C_{1}, C_{2}, E_{n}, E_{g}, \tau_{0}\right)$ turned out to be sufficient to describe all viscoelastic data.

Acknowledgement We are grateful to Technologiestichting (STW) for sponsoring the project. Thanks to Jan de vreugd, Jos van Driel, Harry jansen, Rob and Patrick for their support.

Open Access This article is distributed under the terms of the Creative Commons Attribution Noncommercial License which permits any noncommercial use, distribution, and reproduction in any medium, provided the original author(s) and source are credited.

\section{References}

1. Banks L, Ellis B (1982) The glass transition temperature of highly crosslinked networks: Cured epoxy resins. Polymer 23:1466-1472

2. Bellenger V, Dhaoui W, Verdu J, Galy, Won YG, Pascault JP (1989) Glass transition temperature predictions for nonstoichiometric epoxide-amine networks. Polymer 30:2013-2018

3. Bellenger V, Verdu J (1987) Effect of structure on glass transition temperature of amine crosslinked epoxies. J Polym Science B Polymer Phys 25:1219-1234

4. Crawford E, Lesser AJ (1998) The effect of network architecture on the thermal and mechanical behavior of epoxy resins. J Polym Sci Part B Polym Phys 36:1371-1382

5. Fox TG, Flory PJ (1950) Second-order transition temperature and related properties of polystyrene. J Appl Phys 21:581-591

6. Gerard JF, Galy J, Pascault JP, Cukierman S, Halary JL (1991) Viscoelastic response of model epoxy networks in the glass transition temperature. Polym Eng Sci 31:615-620

7. Gupta VB, Brahatheeswaran C (1991) Molecular packing and free volume in crosslinked epoxy networks. Polymer 32:1875-1884

8. Halary JL (2000) Structure-property relationships in epoxy-amine networks of well-controlled architecture. High Perform Polym $12: 141-153$

9. Hill LH (1997) Calculation of crosslink density in short chain networks. Prog Org Coat 31:235-243

10. Ferry JD (1976) Viscoelastic Properties of Polymers, 3rd edn, pp. 271

11. Jansen KMB et al (2006) Effect of resin formulation on thermoset viscoelasticity. Eng Mater Technol 128:478-483

12. Macosko CW, Miller DR (1976) A new Average molecular weights of nonlinear polymers. Macromolecules 9:199-206

13. Miller DR, Macosko CW (1976) A new derivation of postgel properties of network polymers. Macromolecules 9:206-211

14. Nakka JS, Jansen KMB, Ernst LJ, Jager WF (2008) Effect of the epoxy resin chemistry on the viscoelasticity of its cured product. $\mathrm{J}$ Appl Polym Sci 108:1414-1420

15. Nielsen LE (1969) Cross-linking effect on physical properties of polymers. J Macromol Sci, Chem C3(1)1:69-103

16. Nielsen LE (1994) Mechanical properties of polymers and composites, 2nd ed., revised and expanded, pp. 141

17. Plazek DJ (1996) Bingham medal address: Oh, thermorheological simplicity, wherefore art thou? J Rheol 40(6):987-1014

18. Szabo JP, Keough IA (2002) Method for analysis of dynamic mechanical analysis data using the Havriliak-Negami model. Thermochemica Acta 392-393:1-12

19. Vakil UM, Martin GC (1992) Crosslinked epoxies: network structure characterization and physical-mechanical properties. J Appl Polym Sci 46:2089-2099 